\title{
Epidemiological Characteristics of Pandemic Coronavirus Disease (COVID-19) in Oman
}

Bader Al-Rawahi, ${ }^{1}$ "Prakash K. P., ${ }^{1}$ Adil Al-Wahaibi, ${ }^{1}$ Amina Al-Jardani, ${ }^{1}$ Khalid Al-Harthy, ${ }^{1}$ Padmamohan J. Kurup, ${ }^{1}$ Ali Al-Moqbali, ${ }^{2}$ Mohammad Al-Tubi, ${ }^{3}$ Zayid Al-Mayahi, ${ }^{4}$ Amal Al-Maani, ${ }^{1}$ Seif Al-Abri ${ }^{1}$

\begin{abstract}
Objectives: The aim of the current study was to describe COVID-19's epidemiological characteristics in Oman during the initial stages of the outbreak and compare findings with other countries' reports. Methods: Data were drawn from a descriptive, records-based review of reported cases of COVID-19 collected through the national COVID-19 Surveillance System from February to April 2020. Results: A total of 2,443 confirmed cases were reported during the study period. The overall first-time testing rate for this period was 851.7 per 100,000 , the positivity rate was 53.1 (confidence intervals [CI]: 51.0-55.2) and the death rate was 0.32 (CI: 0.20-0.54) per 100,000 population, respectively. The overall national positive ratio was $5.7 \%$ and ranged from $2.2-7.1 \%$ across various governorates. Muscat Governorate had the highest positive ratio (12.5\%). People in the 51-60 year old age group ( $R R=1.97)$, males $(R R=1.24)$, non-Omanis $(R R=2.33)$ and those living in Muscat $(R R=2.14)$ emerged as categories with significant demographic risk for COVID-19 cases when compared to the national average. The mean age was 35.6 \pm 13.4 . Asymptomatic cases accounted for nearly 16\%. Conclusion: The overall rate of COVID-19 cases and deaths were low in Oman compared to the rest of the world during the study period.
\end{abstract}

Keywords: Coronavirus; COVID-19; SARS-CoV2; Epidemiology; Pandemic; Oman.

\section{AdVANCES IN KNOWLEDGE}

This study showed the incidence of COVID-19 and the resulting death rate is low in Oman compared to the rest of the world. This study also identified the various high-risk groups, such as the elderly, those with co-morbidities, the expat population and those living in certain geographic areas, associated with the increased risk of having COVID-19 infection in Oman.

\section{Application to Patient Care}

Incidence, positivity and death rates help assess the magnitude of the COVID-19 problem in Oman

Improved understanding of incidence rates and positive-to-negative ratio of COVID-19 in Oman can prompt resource allocation and preparedness activities.

Gender, nationality and governorate analysis help in allocating resources and contribute to implementing prevention and lockdown strategies.

Epidemiological information will aid in establishing COVID-19 patient care centres and quarantine strategies.

Clinical presentations will help modify case definitions and the application of infection control measures accordingly.

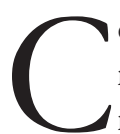
oronaviruses are a group of related ribonucleic acid (RNA) viruses present in mammals, birds and bats, with bats being particularly known as reservoirs of SARS-like coronaviruses. These viruses can cause respiratory tract infections that range from mild to severe in humans. Several coronaviruses-229E, HKU1, NL63 and OC43-are known to cause mild respiratory disease like the common cold among humans. ${ }^{1}$ However, the recently detected SARS-CoV (2002) and MERS-CoV (2012) viruses have been known to cause severe acute respiratory syndrome and community and healthcare setting outbreaks. ${ }^{2}$

The novel coronavirus, severe acute respiratory syndrome coronavirus 2 (SARS-CoV-2), was first identified in Wuhan City in China's Hubei Province. The World Health Organization (WHO) designated the disease as COVID-19. ${ }^{3}$ It spread rapidly, resulting in an epidemic within China, and later spread to other countries. The L type of SARS-CoV-2 predominated during the early days of the epidemic in China within the Wuhan City boundaries. ${ }^{4}$ The virus has shown an affinity for cell entry through the angiotensinconverting enzyme 2 (ACE2). ${ }^{5}$

The WHO declared the outbreak a public health emergency of international concern on 30 January 2020 and on March 11, it was declared a pandemic.3,6,7 As per an 11 May 2020 situation report, nearly four million cases had been reported across 187 countries and territories, resulting in more than 279,000 deaths worldwide. Globally, the case fatality rate was $3.4 \%$ of reported COVID-19 cases. At the time of writing, the European region had the highest number of cases followed by the Americas. The USA had the greatest 
number of cases (1.2 million) and 76,916 deaths. ${ }^{8}$ Worldwide numbers varied by region and country and were influenced by the volume of testing, healthcare system quality, treatment options, time since initial outbreak and population characteristics.

The first case was confirmed in Oman on 24 February 2020 when two citizens tested positive for COVID-19 after returning from Iran. The main objective of this article is to describe the epidemiological characteristics of COVID-19 during the study period of the pandemic and compare the findings with other countries to facilitate prevention and control measures.

\section{Methods}

This record-based description reports COVID-19 cases occurring throughout Oman between 1 February and 30 April 2020. A person with laboratory confirmation of the SARS-CoV2 virus causing COVID-19 infection, irrespective of clinical signs and symptoms, was considered a confirmed case. All epidemiological and clinical events related to COVID-19 patient characteristics such as age, gender, nationality, clinical features and geographic distribution were considered.

The data were collected electronically as part of Oman's Ministry of Health's national COVID-19 surveillance system. Standard case definitions were used and all cases were included without any exclusion criteria. All serious events, including clusters, were investigated within a realistic timeframe.

Cases were entered into the electronic system by doctors, nursing staff, regional epidemiologists and/ or public health staff on possible exposures along with epidemiological investigations. Comorbid conditions were recorded as self-reported patient medical history. Disease severity was classified as mild/moderate, severe or critical based on the clinical and laboratory findings. ${ }^{9}$

The voluntarily reported start of symptoms of either fever and/or cough, based on the date of onset, was used to draw the epidemiological curve. Cases in Oman were categorised by province. Asymptomatic cases were defined as people not showing any COVID-19 symptoms such as fever and respiratory symptoms and were identified largely through close contact screening.

Respiratory samples were collected from all suspected cases by trained health care personnel and placed immediately into a sterile transport tube containing $2-3 \mathrm{~mL}$ of viral transport medium or universal transport medium. The sample was immediately stored at a $2-8^{\circ} \mathrm{C}$ cold chain and transported within 24-72 hours to the Central
Public Health Laboratory in Muscat. The samples then went through reverse transcription polymerase chain reaction (RT-PCR) testing using different kits following an extraction and amplification process.

Microsoft Excel (Microsoft, Redmond, Washington, USA) was used for data compilation and analysis was performed using Statistical Package for the Social Sciences (SPSS), Version 21.0 (IBM, Corp., Armonk, New York, USA). Oman's estimated 2018 population was used to calculate the average annual population-based rates for different variables. ${ }^{10}$ Mean \pm two standard deviations (SD) was calculated for continuous variables such as age. Positivity rate was recorded as positive cases per 100,000 population. The positive ratio was considered the number of positive cases divided by the number tested. Case fatality rates (proportion, \%) were calculated as the total number of deaths divided by the total number of cases. Using the national average as a reference, the confidence interval (CI) for the difference between proportions calculated was used to compare the group variables and relative risk (RR). Additionally, a 95\% CI was also calculated using the following website: https://www.pedro.org.au/ wp-content/uploads/CIcalculator.xls. An RR >1 was considered statistically significant.

The Director General for Disease Surveillance and Control of the Ministry of Health of Oman approved the study.

\section{Results}

In total, 41,831 suspected cases were identified through Oman's national COVID-19 surveillance system during the study period. A total of 1,220 (2.9\%) samples were excluded from the analysis because they did not meet the case definition for testing. In total, 2,656 samples (6.5\%) were identified for repeat testing. Of the 39,195 non-repeat samples tested, the positive ratio was $5.7 \%$. The majority, $94.2 \%$, tested negative for SARS-CoV-2 ribonucleic acid (RNA) by polymerase chain reaction (PCR). Inconclusive results were seen in $0.1 \%$ of suspected cases.

The overall first-time testing rate (excluding repeat testing for the same patient) for this period was 851.7, and the positivity rate was 53.1 (CI: 51.0-55.2). The death rate from COVID-19 was 0.32 (CI: 0.200.54) per 100,000 total population. The testing covered nationals and non-nationals from 97 countries with the majority of the non-nationals being working residents from Asian countries. The positive ratio was higher (13.3\%) among non-nationals compared to the Omani population (2.8\%).

The positive ratio according to the International Organization for Standardization (ISO) week number 


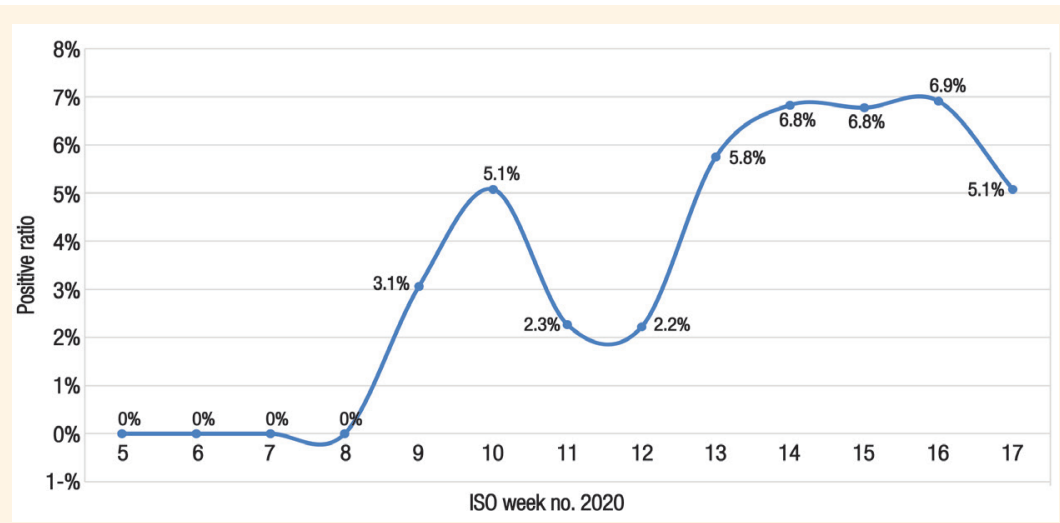

Figure 1: COVID-19 testing positivity ratio by the International Organisation for Standardisation (ISO) week number in Oman between February and April 2020.

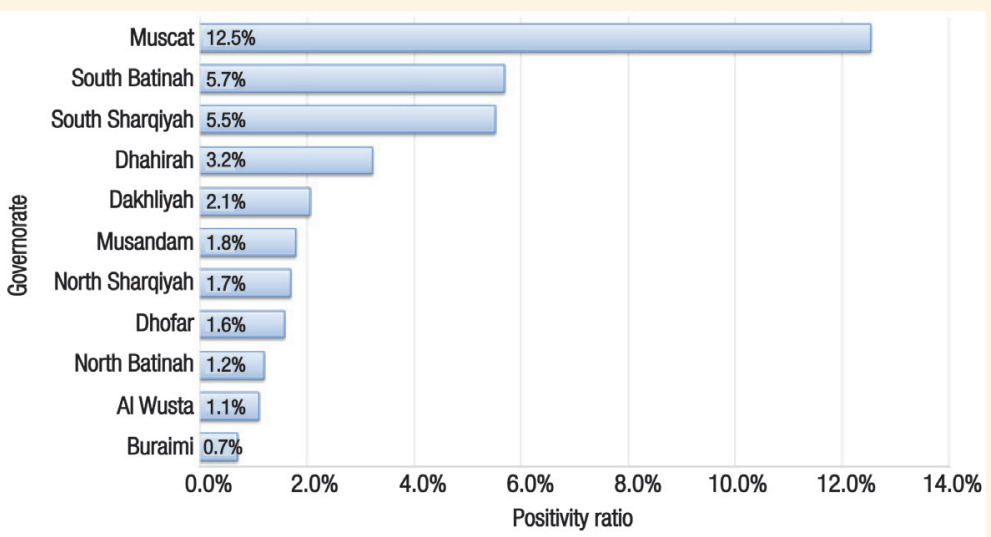

Figure 2: COVID-19 testing positivity rates by governorate in Oman between February and April 2020.

and governorate from the beginning of the outbreak is shown in Figures 1 and 2. As shown in Figure 1, the positive ratio started to peak during week 10 and reached around $6.9 \%$ by week 16 .

The positive ratio ranged from $0.7-12.5 \%$ in different governorates. Muscat Governorate had the highest positive ratio (12.5\%), whereas the lowest was in Buraimi (0.7\%). Of the total tested samples, $87.9 \%$ and $12.1 \%$ were tested within 24 hours and two days of sample collection, respectively. The results were reported within 24 hours from receiving samples in $84.7 \%$ of cases, within two days in $11.6 \%$ of cases and after two days in $3.7 \%$ of cases.

A total of 2,443 COVID-19 (SARS-CoV-2 RNA by PCR) confirmed cases were reported during the study period from 40,611 suspected tested cases reported through the COVID-19 surveillance system. The male-to-female ratio was 3.9:1. The frequency distribution of cases by age, gender and governorate is shown in Table 1. The maximum number of cases were among those aged $31-40$ years (36.2\%), followed by $21-30(24.2 \%)$ and $41-50$ years $(17.7 \%)$. Males (79.6\%), non-Omanis (61.5\%) and people from the Muscat Governorate (71.5\%) were the most commonly affected groups.
The reporting rate was significantly higher among those in the 31-70-year-old age groups (73.1-85.4/100,000 population) compared with the national average (53.1/100,000 population). Certain populations, such as those in the $51-60$ year old age group ( $R R=1.33$, 95\% CI: 1.09-1.61), males ( $R R=1.24,95 \%$ CI: $1.17-1.32$ ), non-Omanis $(\mathrm{RR}=2.33$, 95\% CI: $2.19-2.47)$ and those living in Muscat ( $R R=2.14,95 \%$ CI: 2.02-2.27) emerged as significant risk demographic categories for COVID-19 cases in Oman when compared to the national average [Table 1].

The frequency age (years) distribution of COVID-19 cases in Oman indicates that middle aged individuals were most commonly affected at the time of writing. The mean and median ages were $35.6 \pm 13.4$ years and 34.0 years, respectively.

Table 2 depicts the number of COVID-19 cases according to clinical features. Asymptomatic individuals accounted for $16 \%$ of the cases in Oman. The most common symptoms were fever, cough, sore throat and/or runny nose. Fever and cough were reported in about $55 \%$ of the symptomatic cases each. Gastrointestinal symptoms such as nausea, vomiting, abdominal pain, diarrhoea and constipation were seen 
Table 1: Descriptive statistics of COVID-19 cases according to age, gender, nationality and governorate in Oman between February and April 2020

\begin{tabular}{|c|c|c|c|c|c|c|}
\hline \multirow[t]{2}{*}{ Variable } & \multirow{2}{*}{$\begin{array}{l}\text { COVID-19 cases } \\
\text { per } 100,000 \text { total } \\
\text { population }^{\mathrm{a}}\end{array}$} & \multirow{2}{*}{$\begin{array}{l}\text { COVID - } 19 \text { cases } \\
\text { per } 1,000 \text { samples } \\
\text { tested }\end{array}$} & \multicolumn{3}{|c|}{ SARS-2 Test Result } & \multirow[t]{2}{*}{ RR (95\% CI) } \\
\hline & & & Positive & Negative & $\%$ total positive & \\
\hline \multicolumn{7}{|l|}{ Age in years } \\
\hline $1-10$ & 11.1 & 14.1 & 87 & 6083 & 3.6 & $0.22(0.18-0.28)$ \\
\hline $11-20$ & 16.7 & 31.2 & 84 & 2610 & 3.4 & $0.50(0.40-0.62)$ \\
\hline $21-30$ & 55.9 & 62.4 & 592 & 8890 & 24.2 & $1.00(0.92-1.10)$ \\
\hline $31-40$ & 73.1 & 76.4 & 885 & 10692 & 36.2 & $1.23(1.14-1.33)^{*}$ \\
\hline $41-50$ & 73.9 & 82.3 & 432 & 4816 & 17.7 & $1.33(1.20-1.46)^{*}$ \\
\hline $51-60$ & 84.4 & 108.8 & 228 & 1867 & 9.3 & $1.97(1.73-2.24)^{*}$ \\
\hline $61-70$ & 85.4 & 82.4 & 96 & 1069 & 3.9 & $1.33(1.09-1.61)^{*}$ \\
\hline $71-80$ & 59.6 & 42.8 & 30 & 671 & 1.2 & $0.69(0.48-0.98)$ \\
\hline$\geq 81$ & 32.9 & 27.4 & 9 & 283 & 0.4 & $0.42(0.22-0.81)$ \\
\hline \multicolumn{7}{|l|}{ Gender } \\
\hline Male & 65.4 & 77.2 & 1944 & 23249 & 79.6 & $1.24(1.17-1.32)^{*}$ \\
\hline Female & 30.7 & 34.9 & 499 & 13780 & 20.4 & $0.56(0.51-0.62)$ \\
\hline \multicolumn{7}{|l|}{ Nationality } \\
\hline Omani & 36.5 & 32.4 & 941 & 28123 & 38.5 & $0.52(0.48-0.56)$ \\
\hline $\begin{array}{l}\text { Non- } \\
\text { Omani }\end{array}$ & 74.3 & 144.3 & 1502 & 8906 & 61.5 & $2.33(2.19-2.47)^{*}$ \\
\hline \multicolumn{7}{|c|}{ Governorate } \\
\hline Muscat & 120.1 & 132.7 & 1747 & 11422 & 71.5 & $2.14(2.02-2.27)^{*}$ \\
\hline $\begin{array}{l}\text { South } \\
\text { Batinah }\end{array}$ & 59.4 & 54.8 & 253 & 4363 & 10.4 & $0.88(0.78-1.00)$ \\
\hline $\begin{array}{l}\text { South } \\
\text { Sharqiyah }\end{array}$ & 39.5 & 58.3 & 125 & 2018 & 5.1 & $0.94(0.79-1.12)$ \\
\hline Dakhiliyah & 23.7 & 21.1 & 112 & 5185 & 4.6 & $0.34(0.28-0.41)$ \\
\hline $\begin{array}{l}\text { North } \\
\text { Batinah }\end{array}$ & 12.2 & 12.3 & 94 & 7540 & 3.8 & $0.19(0.16-0.24)$ \\
\hline Dhahira & 22.2 & 31.9 & 49 & 1489 & 2.0 & $0.51(0.38-0.67)$ \\
\hline $\begin{array}{l}\text { North } \\
\text { Sharqiyah }\end{array}$ & 11.8 & 15.9 & 33 & 2043 & 1.4 & $0.20(0.63-0.81)$ \\
\hline Dhofar & 3.7 & 8.9 & 17 & 1887 & 0.7 & $0.14(0.08-0.23)$ \\
\hline Musandam & 11.1 & 9.1 & 5 & 546 & 0.2 & $0.14(0.06-0.35)$ \\
\hline Buraimi & 4.3 & 18.1 & 5 & 271 & 0.2 & $0.29(0.12-0.69)$ \\
\hline Al Wusta & 6.3 & 11.2 & 3 & 265 & 0.1 & $0.18(0.05-0.55)$ \\
\hline Total & 53.1 & 61.9 & 2443 & 37029 & 100 & \\
\hline
\end{tabular}

$R R=$ relative risk, $C I=$ confidence interval .

$a_{2018}$ population estimate. "Statistically significant.

in about $2.4 \%$ of cases. Anosmia (loss of smell and taste) was present in $2.0 \%$ of the cases.

Of the total COVID-19 cases reported, 7\% $(171 / 2,443)$ had a history of travel to affected countries. This finding was common at the beginning of the outbreak and before the restrictive travel guidelines were enacted. Nearly $34 \%(n=830)$ had a history of travel to the UK followed by the United Arab Emirates ( $\mathrm{n}=357 ; 14.6 \%)$, the USA (6.4\%), Iran (6.4\%), Saudi Arabia (5.3\%), Pakistan (4.7\%) and Tanzania (4.1\%). 
Table 2: Distribution of COVID-19 cases according to the type of clinical presentation in Oman February to April 2020

\begin{tabular}{lc} 
Type of Clinical findings & $\begin{array}{c}\text { Clinical findings } \\
\text { n (\%) }\end{array}$ \\
\hline Asymptomatic & $391(16.0)$ \\
Symptomatic* & $2052(84.0)$ \\
Fever & $1148(55.9)$ \\
Cough & $1135(55.3)$ \\
$\begin{array}{l}\text { Shortness of breath } \\
\begin{array}{l}\text { Other respiratory symptoms (i.e. } \\
\text { sore throat, running nose, sneezing) }\end{array}\end{array}$ & $113(5.5)$ \\
$\begin{array}{l}\text { General symptoms (i.e. headache, } \\
\text { myalgia, fatigue) }\end{array}$ & $260(12.7)$ \\
$\begin{array}{l}\text { Gastrointestinal symptoms (i.e. } \\
\text { nausea, vomiting, diarrhoea, } \\
\text { abdominal pain) }\end{array}$ & $50(2.4)$ \\
$\begin{array}{l}\text { Anosmia (i.e. loss of smell and taste) } \\
\begin{array}{l}\text { Others (i.e. renal, cardiac disease- } \\
\text { related) }\end{array}\end{array}$ \\
$\begin{array}{l}\text { *These numbers exceed 100\% because each patient can have more than } \\
\text { one symptom. }\end{array}$
\end{tabular}

Others had travelled to various Asian, Middle Eastern and European countries.

The majority of the patients' occupational information was not available (83\%). Migrant resident labourers who were living in company accommodations or together in densely populated spaces or who operated small businesses in crowded designated marketplaces, such as the Souq in the Muttrah District of Muscat Governorate, represented the majority of cases. Healthcare workers directly or indirectly involved in hospital care settings (clinics, hospitals, pharmacy, laboratory, etc.) accounted for $2.5 \%(62 / 2,443)$ of the cases.

Nearly all patients were advised to quarantine at home, followed by institutional (3.7\%) and hospital $(0.8 \%)$ quarantine. In the majority of cases, the place/ source of contact was not known (59.3\%). The place of contact with known COVID-19 cases was in workplaces (12.9\%) followed by among family contacts (12.3\%).

The outbreak in Oman started when the first imported case-an individual with a history of travel to Iran-was diagnosed on 2 February 2020. While the epidemic curve peaked in April 2020 [Figure 3], the number of cases remained constant throughout April. Of the COVID-19 patients, 7\% approximately ( $\mathrm{n}=$ 172 ) had comorbidities. However, $36.6 \%(n=894)$ of recorded cases included no information on associated illnesses. Of the comorbid conditions, hypertension (HTN) accounted for 21.2\% $(\mathrm{n}=518)$ and diabetes mellitus (DM) for 18\% ( $\mathrm{n}=440)$ and DM and HTN coexisted in $25.5 \%$ of cases $(n=623)$. Eleven patients were pregnant at the time of diagnosis. Cancer as well as renal and cardiac disease each coexisted in about $2 \%$ of cases $(n=49$ each). A total of 15 deaths occurred among the 2,443 confirmed cases at the time of writing. The overall case fatality rate was found to be $0.61 \%$ or 0.32 per 100,000 population.

\section{Discussion}

A highly infectious disease, COVID-19 spread very quickly, taking only 30 days to be transmitted from Hubei to the rest of mainland China and then throughout the world within the next couple of months. In Oman, as per Ministry of Health policy, the notification of all priority infectious diseases within 24 hours, including rare and novel infections, is mandatory. ${ }^{11}$

The COVID-19 reporting rate per 100,000 population was 53.1. The reporting rates were significantly higher among the 31-70-year-old age groups, males, non-Omanis and those living in the Muscat Governorate. Given that COVID-19 is a new disease, there is not enough published scientific data to compare with other countries as per the population rates at this point in time. The incidence of COVID-19

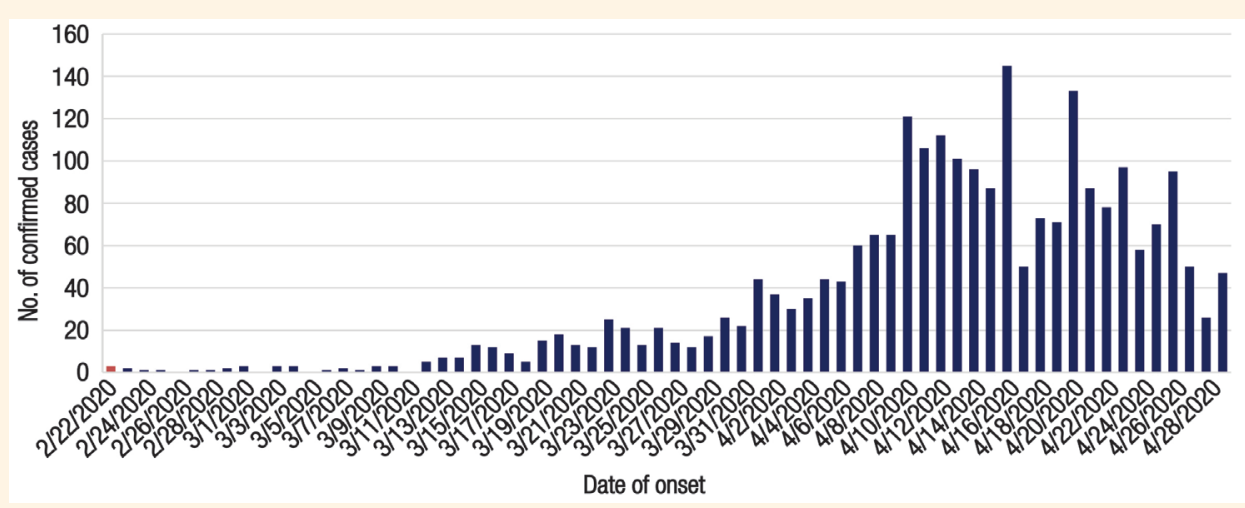

Figure 3: Confirmed COVID-19 cases by date of onset in Oman between February and April 2020. 
which is confirmed based on rapid testing- (RT-) PCR is influenced by the testing countries' criteria and guidelines. In a passive surveillance system, under-reporting can be an important factor and the true extent of the spread of the disease can only be known by the seroprevalence studies using antibody testing. Seroprevalence studies in Iran and California have shown a higher prevalence than reported in this study. ${ }^{12,13}$

Similar to studies from China, the middle-aged population (aged 31-70 years) in Oman was more commonly affected by COVID-19 compared to children and young adults. ${ }^{14,15}$ The infection rates were low $(0.8 \%-4.0 \%)$ among children and young adults in Turkey which is comparable to the current study. ${ }^{16}$

The positive ratio varied according to the ISO week [Figure 1]. This wide variation and decrease or increase in trend is because of testing policy change during these periods such as lockdown, case definition changed by the policy makers.

The number of COVID-19 cases was significantly higher among males than females and this is similar to a report from China. ${ }^{9}$ In the current study, $16 \%$ of the SARS-CoV2 positive patients were asymptomatic. A similar observation was made in studies by Chinese researchers. ${ }^{16,17}$ In the Diamond Princess Cruise Ship study in Japan, asymptomatic cases accounted for $18 \%$ of those tested. ${ }^{18}$ However, according to two Chinese studies, the asymptomatic infection rate was $5 \%$ and $1 \%$, which is low compared to the current study. ${ }^{15,19}$

Asymptomatic cases in Oman resulted from familial clusters or institutional outbreaks. A large number of migrant workers live in company accommodations (camps) similar to the setting reported by the study of Zhang et al. ${ }^{20}$ This variation in asymptomatic cases is due to the testing policy and the demographic characteristics of the country's population. In Oman, nearly 44\% of residents are part of the expatriate working population and are largely middle aged and residing in Muscat Governorate. Crowded living conditions and the presence of this demographic could explain the greater number of COVID-19 cases from Muscat Governorate and in non-Omanis. Additionally, some healthcare facilities tested all close contacts of confirmed SARS-CoV2 cases irrespective of signs and symptoms.

The overall global case fatality rate was $6.3 \%$ as per the World Health Organization (WHO) situation report. ${ }^{21}$ However, the mortality rates varied between countries. ${ }^{8}$ It was noted that the rate was higher in countries with a higher proportion of older individuals. In Italy, the median age of those who died was 78 years, whereas the median age of Omani cases was $62 . .^{22}$ In Turkey, the case fatality rate is $2.1 \%$. Hence, COVID-19 mortality is multifactorial. The presence of underlying disease or healthcare burden and age demographics could be related to higher mortality rates. ${ }^{23}$

A meta-analysis reported that common comorbidities like HTN, cardiovascular disease, DM, smoking, chronic obstructive pulmonary disease, malignancy and chronic kidney disease were associated with COVID-19 morbidity and mortality. ${ }^{14,24,25}$ Similarly in the current study, the most common comorbidity was HTN (21.2\%), followed by DM (17\%) and cardiovascular diseases (11.9\%), which is a similar finding to numerous studies. ${ }^{24,26,27}$

The most common symptoms in this study included fever (55.9\%) and cough (55.3\%); these symptoms are similar to those found in other viral respiratory diseases. However, the presentation of myalgia, sore throat, nausea, vomiting and diarrhoea may suggest other coexisting infections. Viral respiratory coinfection was found to be rare..$^{24,28-32}$

The outbreak resulted in an unprecedented chain of events in Oman in terms of prevention and control measures such as cancellation of air travel, restriction of people's movements and closure of nonessential services and places of mass congregation. The pandemic has also caused healthcare delivery and communicable disease surveillance and control systems to be stretched to the limit.

Many other risk factors for COVID-19 such as comorbidity and occupation were not studied due to limitations around the availability of detailed data in the initial stages of the pandemic. It is anticipated that the current study's results reflect the true picture and scale of the pandemic COVID-19 outbreak in Oman. These findings will help determine future courses of action and guidelines in controlling and/or preventing future epidemics in Oman. Because the COVID-19 outbreak has yet to end, updates should be closely monitored including the disease and risk factors as well as treatment options.

\section{Conclusions}

This study described the epidemiological characteristics during the initial phase of the COVID-19 pandemic in Oman. Fortunately, the disease rate and mortality are low in Oman and the majority affected are asymptomatic or have only mild symptoms, are middle-aged or are previously healthy people without any underlying chronic diseases.

\section{ACKNOWLEDGEMENTS}

The authors are appreciative of all the doctors, nurses, laboratory staff and governorate public health staff who participated in the reporting and investigation of COVID-19 cases. All the disease surveillance and 
control staff at the national level and at the governorate level are thanked for the compilation of data. The researchers express their gratitude to all the private and non-MoH organisations for actively contributing to surveillance system reporting. Their sincere thanks also go to the information technology staff for their continuous support of the health information system.

The following authors has also contributed to this work: Fatma Al-Yaquobi, ${ }^{1}$ Sulien Al-Khalili, ${ }^{1}$ Samir Shah, ${ }^{1}$ Zeyana Al-Habsi, ${ }^{1}$ Sabria Al-Marshoudi, ${ }^{1}$ Abdullah Al-Manji, ${ }^{1}$ Hanan Al-Kindi, ${ }^{1}$ Azza AlRashdi, ${ }^{1}$ Intisar Al-Shukri, ${ }^{1}$ Samira Al-Mahrooqi, ${ }^{1}$ Weam Nazer, ${ }^{1}$ Lamia Al-Balushi, ${ }^{2}$ Salim Al-Katheri, ${ }^{2}$ Sultan Al-Busaidi, ${ }^{2}$ Mahmood Al-Skaiti, ${ }^{2}$ Nawal AlShehhi, ${ }^{2}$ Issam Murqos, ${ }^{2}$ Iyad Omer, ${ }^{2}$ Ahmed AlBalushi ${ }^{2}$. Lastly, all those who have directly or indirectly contributed to this study deserve recognition and thanks.

\section{CONFLICT OF INTEREST}

The authors declare no conflicts of interest.

\section{FUNDING}

No funding was received for this study.

\section{References}

1. Fung TS, Liu DX. Human coronavirus: Host-pathogen interaction. Annu Rev Microbiol 2019; 73:529-57. https://doi.org/10.1 146/annurev-micro-020518-115759.

2. Bulut C, Kato Y. Epidemiology of COVID-19. Turk J Med Sci 2020; 50:563-70. https://doi.org/10.3906/sag-2004-172.

3. World Health Organization. Director-General's remarks at the media briefing on 2019-nCoV 2. Centers for Disease Control and Prevention. 2019 novel coronavirus, Wuhan, China. Information for Healthcare Professionals. From: www.cdc.gov/corona virus/2019-nCoV/hcp/index.html Accessed: Nov 2020.

4. Jin Y, Yang H, Ji W, Wu W, Chen S, Zhang W, et al. Virology, epidemiology, pathogenesis, and control of COVID-19. Viruses 2020; 12:372. https://doi.org/10.3390/v12040372.

5. Zhou P, Yang XL, Wang XG, Hu B, Zhang L, Zhang W, et al. A pneumonia outbreak associated with a new coronavirus of probable bat origin. Nature 2020; 579:270-3. https://doi. org/10.1038/s41586-020-2012-7.

6. World Health Organization. Statement on the second meeting of the International Health Regulations (2005) Emergency Committee regarding the outbreak of novel coronavirus (2019-nCoV). From: www.who.int/news-room/detail/30-012020-statement-on-the-second-meeting-of-the-internationalhealth-regulations-(2005)-emergency-committee-regardingthe-outbreak-of-novel-coronavirus-(2019-ncov) Accessed: Nov 2020.

7. World Health Organization. Press release 11 March 2020. From: www.who.int/emergencies/diseases/novel-coronavirus-2019/ events-as-they-happen Accessed: Nov 2020.

8. World Health Organization. Coronavirus disease (COVID-19) Situation Report-112. From: www.who.int/docs/default-sour ce/coronaviruse/situation-reports/20200511-covid-19sitrep-112.pdf?sfvrsn=813f2669_2 Accessed: Nov 2020.
9. The Novel Coronavirus Pneumonia Emergency Response Epidemiology Team. The epidemiological characteristics of an outbreak of 2019 novel coronavirus diseases (COVID-19)China. China CDC Weekly 2020; 2:113-22. From: weekly. chinacdc.cn/ en/article/id/e53946e2-c6c4-41e9-9a9b-fea8db1a 8f51 Accessed: Nov 2020.

10. Annual Health Report. Demographic features, introduction chapter one. Muscat: Ministry of Health, Oman, 2018. Pp. $1-10$.

11. Manual on Communicable Diseases Manual. Directorate General for disease surveillance and control (DGDSC), 2017, introduction chapter, 3rd ed. Muscat: Ministry of Health, Oman, 2017. pp. 14-34.

12. Shakiba M, Hashemi Nazari SS, Mehrabian F, Rezvani SM, Ghasempour Z, Heidarzadeh A. Sero-prevalence of COVID-19 virus infection in Guilan province, Iran. From: https://doi.org/1 0.1101/2020.04.26.20079244 Accessed: Nov 2020.

13. Bendavid E, Mulaney B, Sood N, Shah S, Ling E, BromleyDulfano R, et al. COVID-19 antibody sero-prevalence in Santa Clara County, California. From: doi.org/10.1101/2020.04.14.20 062463 Accessed: Nov 2020.

14. Yang J, Zheng Y, Gou X, Pu K, Chen Z, Guo Q, et al. Prevalence of comorbidities in the novel Wuhan coronavirus (COVID-19) infection: A systematic review and meta-analysis. Int J Infect Dis 2020; 94:91-5. https://doi.org/10.1016/j.ijid.2020.03.017.

15. Wu Z, McGoogan JM. Characteristics of and important lessons from the coronavirus disease 2019 (COVID-19) outbreak in China: Summary of a report of 72,314 cases from the Chinese Center for Disease Control and Prevention. JAMA 2020; 7:1239-42. https://doi.org/10.1001/jama.2020.2648.

16. Dong $\mathrm{Y}, \mathrm{Mo} \mathrm{X}, \mathrm{Hu} \mathrm{Y}$, Qi X, Jiang F, Jiang Z, et al. Epidemiology of COVID-19 among children in China. Pediatrics 2020; 145:e20200702. https://doi.org/10.1542/peds.2020-0702.

17. Hu Z, Song $\mathrm{C}, \mathrm{Xu} \mathrm{C}$, Jin $\mathrm{G}$, Chen $\mathrm{Y}, \mathrm{Xu} \mathrm{X}$, et al. Clinical characteristics of 24 asymptomatic infections with COVID-19 screened among close contacts in Nanjing, China. Sci China Life Sci 2020; 63:706-11. https://doi.org/10.1007/s11427-0201661-4.

18. Mizumoto K, Kagaya K, Zarebski A, Chowell G. Estimating the asymptomatic proportion of coronavirus disease 2019 (COVID-19) cases on board the Diamond Princess Cruise Ship, Yokohama, Japan, 2020. Euro Surveill 2020; 25. https://doi.org/10.2807/15 60-7917.ES.2020.25.10.2000180.

19. Tian SJ, Hu N, Lou J, Chen K, Kang X, Xiang Z, et al. Characteristics of COVID-19 infection in Beijing. J Infect 2020; 80:401-6. https://doi.org/10.1016/j.jinf.2020.02.018.

20. Zhang J, Tian S, Lou J, Chen Y. Familial cluster of COVID-19 infection from an asymptomatic. Crit Care 2020; 24:119. https://doi.org/10.1186/s13054-020-2817-7.

21. World Health Organization. Coronavirus disease 2019 (COVID-19) Situation Report-84. From: www.who.int/docs/default-source/ coronaviruse/situation-reports/20200413-sitrep-84-covid-19. pdf?sfvrsn=44f511ab_2 Accessed: May 2020.

22. Istituto Superiore di Sanità (2020). Characteristics of COVID-19 patients dying in Italy (based on available data on April 2, 2020). From: www.epicentro.iss.it/en/coronavirus/bollettino/ReportCOVID-2019_2_april_2020.pdf Accessed: Nov 2020.

23. Ji Y, Ma Z, Peppelenbosch MP, Pan Q. Potential association between COVID-19 mortality and health-care resource availability. Lancet Glob Health 2020; 8:E480. https://doi. org/10.1016/S2214-109X(20)30068-1.

24. Siordia JA Jr. Epidemiology and clinical features of COVID-19: A review of current literature. Jr J Clin Virol 2020; 127. https:// doi.org/10.1016/j.jcv.2020.104357. 
25. Emami A, Javanmardi F, Pirbonyeh N, Akbari A. Prevalence of underlying diseases in hospitalized patients with COVID-19: A systematic review and meta-analysis. Arch Acad Emerg Med 2020; 8:e35.

26. Guan WJ, Ni ZY, Hu Y, Liang WH, Ou CQ, He JX, et al. Clinical characteristics of 2019 novel coronavirus infection in China. N Engl J Med 2020; 382:1708-20. https://doi.org/10.1056/ NEJMoa2002032.

27. Huang C, Wang Y, Li X, Ren L, Zhao J, Hu Y, et al. Clinical features of patients infected with 2019 novel coronavirus in Wuhan, China. Lancet 2020; 395:497-506. https://doi. org/10.1016/S0140-6736(20)30183-5.

28. Zhao X, Zhang B, Li P, Ma C, Gu J, Hou P, et al. Incidence, clinical characteristics and prognostic factor of patients with COVID-19: A systematic review and meta-analysis. From: www.medrxiv.org/content/10.1101/2020.03.17.20037572v1. full.pdf Accessed: Nov 2020.
29. Woelfel R, Corman VM, Guggemos W, Seilmaier M, Zange S, I Mueller MA, et al. Clinical presentation and virological assessment of hospitalized cases of coronavirus disease 2019 in a travel-associated transmission cluster. From: https://www.med rxiv.org/content/10.1101/2020.03.05.20030502v1 Accessed: Nov 2020.

30. Ai JW, Chen J, Wang Y, Liu X, Fan W, Qu G, et al. The crosssectional study of hospitalized coronavirus disease 2019 patients in Xiangyang, Hubei Province. MedRxiv 2020. From: https:// www.medrxiv.org/content/10.1101/2020.02.19.20025023v1 Accessed: Nov 2020.

31. Chen X, Zheng F, Qing Y, Ding S, Yang D, Lei C, et al. Epidemiological and clinical features of 291 cases with coronavirus disease 2019 in areas adjacent to Hubei, China: A double-center observational study. From: https://www.medrxiv.org/content/10. 1101/2020.03.03.20030353v1 Accessed: Nov 2020.

32. Lin D, Liu L, Zhang M, Hu Y, Yang Q, Guo J, et al. Co-infections of SARS-CoV-2 with multiple common respiratory pathogens in infected patients. Sci China Life Sci 2020; 63:606-9. https:// doi.org/10.1007/s11427-020-1668-5. 